\title{
Mobile Technologies in Education
}

\author{
Zablotska L. \\ PhD, Associate Professor at \\ Ternopil V. Hnatiuk National Pedagogical University, Ukraine \\ Chernii L. \\ PhD, Associate Professor at \\ Ternopil V. Hnatiuk National Pedagogical University, Ukraine \\ Meleshchenko V. \\ PhD, Associate Professor at \\ Ternopil V. Hnatiuk National Pedagogical University, Ukraine
}

\begin{abstract}
The informatization of education is one of the priorities on the path to open education and is an indicator of the development of modern society. The use of information tools in education, including mobile technologies, creates conditions for the implementation of the educational process and ensures its continuity by integrating traditional and distance learning, which is especially relevant today, in quarantine times, when many educational institutions use distance or blended (combined) form of education. The aim of the article is to understand the notion of mobile education and its influence on current development of educational processes in higher educational institutions in Ukraine.
\end{abstract}

Key words: information technologies, education, mobile education

Globalization processes have an impact on the economy, politics, and social lifestyle. The rapid digital revolution and the digitization of all aspects of life influence the development of the national education system at all levels. With the spread of COVID-19 today, education has been converted into an online format. As a result, the issue of using mobile devices, gadgets, and Web-based technologies in the learning process has become more challenging than ever before.

In 1968 Alan Kay and colleagues at the Xerox PaloAlto Research Center in California suggested the use of a specific type of mobile device. They wanted to create the Dynabook, a "personal computer for children of all ages" that could combine the power of computers and phones. Soon, the study of the possibilities of using mobile tools in the learning process began in Europe too (when the first mobile devices appeared). Later it was highlighted in the researches of B.Alexander, M.Ally, A.Baker, D.Corlett, C.Dede, J.Evans, M.Sharples, and I.Traxler. 
Ukraine has made significant progress in technological development in recent decades. The number of regular Internet users since 2019 is growing by $15-20$ percent every year. The main reasons for this are widespread use of smartphones. In 2021, the smartphone became the first and the only device for 22 percent of new users to access the Internet. The most active Internet users are Ukrainians aged 15 to 24 (above 97\% are Internet users), people aged 25 to $34-96 \%$, above 65 - already $29 \%$ (a year ago it was only 14\%)" [1].

The introduction of information technology to modern education system has led to the emergence of the latest information, pedagogical and educational technologies that make learning process more flexible, accessible, individualized and democratic. These changes also help to adopt the concept of open education that is gradually implemented in Ukraine. According to O. Ovcharuk among basic features of open education systems are: 1) the emergence of new opportunities for the development of educational content and pedagogical technologies; 2) access to all levels of education; 3) access to education for all, especially for those who cannot study at universities due to lack of financial or physical disabilities, professional employment, remoteness from large cities, etc.; 4) creating conditions for the implementation of the concept of lifelong learning [2].

The enormous popularity of mobile communications devices and the Internet undoubtedly has led to the rethinking of their place and role in the educational process. One of the focuses is the modernization of education, which is based on the adoption of innovative teaching methods. Nowadays, teachers have a task to create such learning environment in which students can master their practical skills. Teachers and scientists are constantly conducting research, searching for new methods, technologies, and forms of teaching to optimize and modernize the learning process [3].

The notion of mobile learning (m-learning) emerged in the early $21^{\text {st }}$ century, when mobile phones, computers, tablets, and other portable devices entered people's lives and became the basic means of communication. The holistic concept of mobile learning was introduced by D. Keegan in 2001. Subsequently, the European Under the direction of M. Sharples, the Commission initiated the MOBIlearn project which formulated the main idea of the project "What is educational is mobile" [2] and defined the conditions for mobile learning. In 2002, The m-Learning Consortium was established in Canada, and the state standard for mobile learning was adopted in Australia. In 2004, Intel launched the Learning Always and 
Everywhere project, which aims to provide each student with personal access to mobile computing devices and wireless communication in schools [4].

The situation has changed slightly with the introduction of the BYOD concept ("bring your own device"). This concept was developed in 2009 at Intel in response to the trend of employees using their own mobile devices in the workplace. The term "Bring Your Own Device" (BYOD) was strengthened in 2011 as a result of the collaboration of Unisys, a major provider of IT solutions, and well-known software vendors, VMware and Citrix (USA). Many progressive educators around the world have taken this concept and begun to employ mobile phones and tablets for educational purposes. At the same time, teachers do not prohibit, but rather encourage, students to bring their devices to class and use them actively during work.

The modern interpretation of the concept of mobile initiation (m-learing) is not unambiguous. There are significant differences among researchers regarding the interpretation of this term. However, all definitions are based on mobile communications. Very often mobile learning is considered in conjunction with other information and communication technologies. It should be noted that the use of mobile technologies for educational purposes is possible both autonomously and in combination with other means, including information and communication technologies (ICT). Mobile learning is usually considered in connection with other forms of information and communication technology. It should be highlighted that mobile technologies can be used for educational purposes both independently and in combination with other methods, such as information and communication technology (ICT).

Mobile learning should be considered as a separate area in the use of ICT in education. The model of ICT use in the education system has always had several technical limitations due to the hardware characteristics of the devices. For example, ICTs have traditionally been associated with personal desktops, and their use has been limited by the cost of this equipment, size and weight, and so on. The development of computer and mobile technologies changes these characteristics, and approaches to the use of ICT in educational environments. This is due to the specific characteristics of using mobile devices to receive, analyze, and transfer data. Here are a few that set mobile technology apart from traditional ICT: mobile devices belong to individuals, not organizations; the availability of mobile technologies is constantly growing; rapid development of related technologies connected with the transmission and storage of information on the Internet (e.g., cloud technology) increases the relevance of mobile devices. 
Nowadays mobile gadgets are penetrating more and more spheres of life, affecting them, changing the ways of delivering information and speeding up its exchange. Modern smart phones, as an increasingly accessible and diverse means of communication, have the potential to make learning more effective, entertaining, and accessible. Furthermore, modern gadgets are equipped with a touch screen and keyboard function, allowing you to combine the functions of several devices in portable one, increasing learning potential.

According to J. Traxler, mobile learning completely transforms the education, as mobile devices not only affect the ways in which content is presented and accessed, but also contribute to the development of new types of cognition and mentality. Learning becomes more timely, sufficient, and tailored to the individual ("just-in-time, just enough, and just-for-me"). These features of mobile learning contrast with those of blended and e-learning (e-learning), in which pedagogic principles such as multimedia, structure or modularity, interactivity, and accessibility supercede. The balance between the learning process and student participation is changing thanks to mobile technologies. As a result, becomes mixed, which characterizes a new wave of human society's informatization development. [5]

In our opinion, the idea of combined use of mobile devices in the educational process is reasonable. It is possible to integrate traditional learning, distance learning, and mobile learning. This model of blended learning is described by researchers from the German company Allconsulting $\mathrm{GmbH}$ [6]. Blended learning means learning through the use of a blend of educational resources. Different approaches to learning - e.g. face-to-face sessions, electronic teaching/ learning concepts like computer-based training (CBT) or e-learning tools and techniques are combined in a didactically sensible way to establish, organized and continually tutored further education arrangement (Fig. 1). 


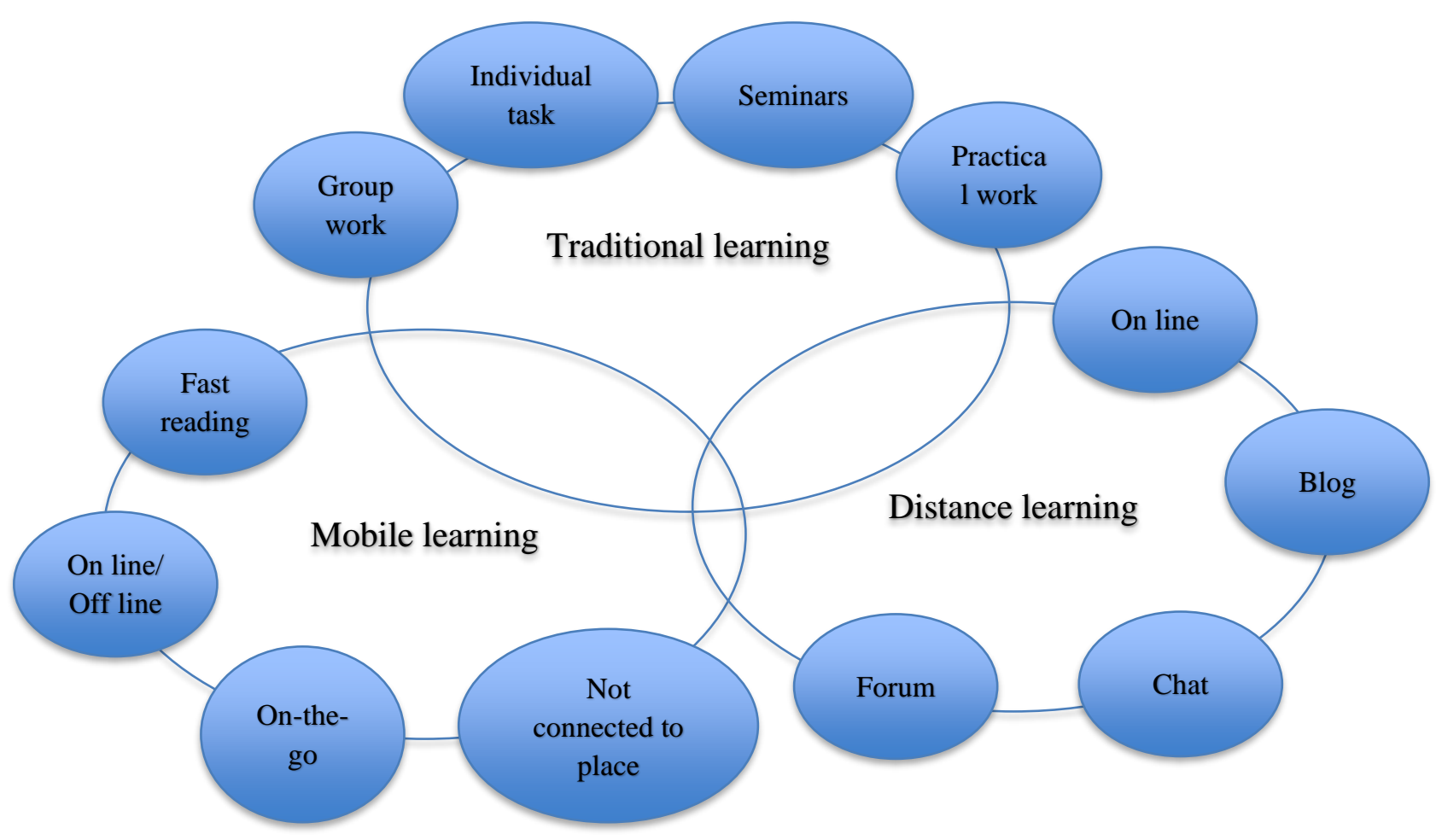

Figure 1. Model of blended learning according to Allconsulting GmbH

As shown in Fig. 1, mobile learning based on the combined learning model opens many possibilities for students. It promotes accessibility and exchange of information and encourages independent work and communication with other learners. Another advantage of modern mobile phones, tablets, netbooks, and other devices is that students (users) can download textbooks, tutorials, programs, and important messages and use them anywhere, not only in classes. In such circumstances, the notion of "on-the-go" learning is applied.

Thus, mobile phones are not just for fun, communication, and entertainment. They can also teach how to learn and encourage to be creative. In general, students have a positive attitude towards mobile learning, and mention that they enjoy the contact and collaboration when completing tasks. That is why, progressive educators in many educational institutions around the world and Europe are actively implement mobile devices into the teaching process, replacing traditional textbooks and notebooks. Such involvement became especially relevant in the conditions of quarantine, when we had to study remotely. Combining information and communication tools with mobile technology has improved the methods and means of accessing educational content as well as the ways it is presented. 


\section{References}

1. Number of Internet users has increased. Retrieved from: https://www.epravda.com.ua/news/2019/10/11/652498/

2. Ovcharyk O. Conceptual approaches to the application of technologies of open education and distance learning in foreign countries and their role in the processes of modernization of education [Electronic resource]. Retrieved from:

http://journal.iitta.gov.ua/index.php/itlt/article/view/292/278

3. Zablotska L., Meleshchenko V., Chernii L. Innovative methods of teaching English for specific purposes in higher education institutions. Engineering and educational technologies. Kremenchuk: KrNU, 2019. T. 7 (3). P.85-95.

4. Teplytskyi I. Basic elements of mobile learning. Information technologies in education, science and technology. Cherkasy, 2008. P.106-107.

5. Traxler J. Current State of Mobile Learning. Retrieved from: http://www.aupress.ca/index.php/books/120155

6. Corporate e-learning. Retrieved from: http://www.allconsulting.de/e-learning-en.html]. 